\title{
The Italian version of the Adult Strabismus-20 (AS-20) questionnaire: translation validation and reliability
}

\author{
Giovanni Battista Marcon ${ }^{1 *}$ and Raffaele Pittino ${ }^{2}$ \\ ${ }^{1}$ Strabismological and Diplopia Center Bassano del Grappa Italy \\ ${ }^{2}$ Casa di Cura Citta' di Udine Udine Italy
}

\begin{abstract}
Objective: To develop a culturally adapted italian version of the Adult Strabismus-20 (AS-20)

Questionnaire Health Survey and to test its acceptability, reliability, and validity in patients with strabismus.

Study design and setting: The English AS-20 was translated italian into after established cross-cultural adaptation procedures.

The questionnaire was administered to 100 consecutive outpatients with strabismus and 38 normal adults and read ministered after 2 weeks to 15 randomly selected patients and 26 visually normal adults.

Results: none of the participants had any problem in understanding the Italian AS-20 and 100\% of the questionnaires were fully completed. The translated questionnaire has good discriminatory power between patients and healthy controls. Principal component analysis confirmed that the hypothesized two-factor structure and tests of scaling assumptions were $90 \%$ successful for all scales. Cronbach's a was higher than 0.78 and the test retest reliability was high ( $\mathrm{r}>0.82$ ) for all scales. Correlations with other disease activity parameters were generally as expected.
\end{abstract}

Conclusion: The Italian AS-20 appears to be an acceptable, reliable, and valid instrument for measuring health-related quality of life in patients with strabismus.

\section{Introduction}

Measurements of health-related quality of life (HRQOL) are increasingly being used in clinical trials and health services research [1,2].

HRQOL measures can be divided into generic and specific measures [3].

Generic measures are not specific to any disease or population, and such measures can be used across various diseases. Specific instruments are specific to a disease, to a population of patients, to a certain function, or to a problem. When considering the application of HRQoL instruments within ophthalmology, there are concerns that generic measures are not sensitive to the recognised symptoms of vision loss or emotional aspects of a given ophthalmic condition, such as strabismus. Among the several specific measures, one instrument that may be used in the investigation and management of patients with strabismus is the Adult Strabismus-20 (AS-20) Questionnaire developed by Sarah R. Hatt et al [4].

With the growing international collaboration in clinical research, the need for cross-culturally applicable instruments for outcome measures has also increased [5].

One approach to meet this need is to translate and culturally adapt measures originally developed in English for use in a different cultural context.

The aim of this study was to develop and evaluate a culturally adapted Italian version of AS-20 Health Survey for use in Italian speaking people. The developed questionnaire was applied in Italian patients with and without strabismus to study its acceptability, reliability, and validity.

\section{Materials and methods}

\section{Original AS-20 questionnaire}

The AS-20 is a patient-derived instrument for use in patients with a diagnosis of strabismus [4]. Subjects with strabismus were interviewed and statements or phrases were used to generate a 181-item questionnaire. A number of items were subsequently removed as they were found to be not applicable. Of the remaining items, two subscales were identified that were applicable to the strabismic population (psychosocial (P) and function (F)), with each subscale containing 10 items. A 5-point Likert type scale is applied to each question. The overall AS-20 is given from 0 (worst HRQoL) to 100 (best HRQoL).

\section{Translation and cultural adaptation of AS-20 questionnaire}

We followed the proposed guidelines by Beaton et al [6] for translation and cross-cultural adaptation of HRQOL measures. Two forward translations of the US English AS-20 into were done by two translators (one Ophthalmologist and another by a naive translator, both with as their mother tongue). A synthetic version was developed

Correspondence to: Giovanni Battista Marcon, Via Bortolo Zonta 14, 36061 Bassano del Grappa (VI), Italy, Tel: +390424521036, +393478414803 ; Fax: +390424511187; E-mail: gbmarcon@nsoft.it

Received: September 29, 2017; Accepted: October 18, 2017; Published: October 21,2017 
by the translators. The synthesized version was back translated into English by a university teacher who worked in UK for 6 years and a professional English translator. Both were masked to the US English version and naive to the concept measured. An expert committee that included health professionals (two Ophthalmologist, two Paediatricians, a Radiologist, a General Medicine Physician, and an Epidemiologist) and the translators involved in the process reviewed all translations and verified the semantic, idiomatic, experiential, and conceptual equivalence between the source and the Italian version. Consensus was reached on any discrepancy, and a preliminary Italian version of the questionnaire was developed for fieldtesting to check face and content validity.

The translation was straightforward for most of the items and response choices except for the P06 item. "I am self conscious about my eyes" because it has a negative nuance that is very difficult to render in Italian language. The best correct translation in Italian should be a duplicate of P03 item "I feel uncomfortable when people are looking at me because of my eyes". For these reasons we chose to literal translate item P06, even if it could be misunderstanding.

\section{Field testing}

The preliminary Italian version of the AS-20 questionnaire was pretested in a convenience sample of 30 patients with strabismus enrolled in the private practice of the authors. After informed consent, the questionnaire was interviewer administered to each subject and was probed on what he or she thought regarding what each item meant and the chosen response. Patients reported no problems answering the original questions, and therefore no further modifications to the instrument were made.

\section{Psychometric evaluation of the Italian AS-20}

Patients and data collection: A new sample of 138 patients (100 patients with strabismus and 38 visually normal adults (without experience in the clinical management of strabismus) were recruited consecutively in the private practice of the authors between March 2012 and March 2013 for the psychometric study. For the test-retest reliability, 41 patients were randomly selected. The study was performed following the declaration of Helsinki principles. Informed consent was obtained from all patients before enrolment. All participants were able to understand and cooperate with the study procedure. Patients having a history of coexisting major illness, psychological illness, or who were unwilling to provide verbal informed consent were excluded. All participants completed the AS-20 in unsupervised manner in the waiting room.

Visual acuity was measured (at $6 \mathrm{~m}$ ) by a projector and optotypes. For each participant, best-corrected visual acuity was extracted from the medical record. Unilateral visual acuity loss (presumably attributable to amblyopia in most cases) was categorized on a 4-point scale: level 1, interocular difference in visual acuity of $\leq 1$ line (0.1 logMAR); level 2 , interocular acuity difference of 2 to 4 lines; level 3, interocular acuity difference of 5 to 7 lines; and level 4 , interocular acuity difference $\geq 8$ lines. The levels of diplopia were assessed by the physician on 4-point scales as follows: level 1, no diplopia; level 2, diplopia in sidegaze or upgaze; level 3, diplopia in primary gaze or downgaze; level 4, constant diplopia. The current angle of strabismus was measured by the alternating prism cover tests during fixation at distance $(6 \mathrm{~m})$ and at near $(30 \mathrm{~cm})$. The angle of horizontal and vertical deviation at distance (prism dioptres (PD) measured with alternate prism cover test) was assessed by the physician on 3-point scales as follows. For horizontal deviation level $1, \leq 10 \mathrm{PD}$; level 2 between 10 and 35 PD; level $3 \geq 35$ PD. For vertical deviation level 1, $\leq 4$ PD; level 2 between 4 and 14 PD; level $3 \geq 14$ PD.
Test-retest assessment: A random sample of 41 patients (15 patients with strabismus and 26 visually normal adults) was interviewed twice using the AS-20 with an interval of 2 weeks. During those 2 weeks, no intervention was given.

\section{Scoring of the AS-20}

All items are measured on Likert-type rating scales. For the purpose of scoring, the rating scales are assumed to be linear and run 0 to 100 , where 0 corresponds to the least favourable score and 100 corresponds to the most favourable score. Intermediate response options are assigned a proportionate score [7].

A five-option item thus has possible scores of $0,25,50,75$, and 100, ranging from unfavourable to favourable. Scores on all items belonging to a subscale are averaged to arrive at the subscale score. The AS-20 total score is defined as the mean of all item scores.

\section{Statistical analysis}

Psychometric evaluations were performed following the approach developed by the International Quality of Life Assessment (IQOLA) project [8].

Descriptive statistics were used to examine the completeness of the data and to characterize the score distributions, including scale ranges, means, standard deviations, and floor and ceiling effects. The discriminant ability of the questionnaire was measured by comparison between patients and controls by the means of the Mann -Whithney test. Internal construct validity was assessed by principal component analysis with orthogonal rotation of the scales and by examining Pearson's correlations between the scales. Two factors (psychosocial and function) have been shown to underlie the structure of the US English version of the AS-20.

Scaling assumptions were examined using the item discriminant validity approach, which is based on a comparison of the magnitude of the correlation of an item with its hypothesized scale as compared with other scales [8].

Item discriminant validity is supported when an item correlates significantly higher (i.e., two standard errors [SEs] or greater) with its own scale (corrected for overlap) than with the other scales. Internal consistency was examined by Cronbach's alpha coefficients and corrected item-scale correlations. Cronbach's alpha coefficient measures the overall correlation between items within a scale and is considered acceptable $>0.70$. Item-scale correlation assesses the extent to which an item is related to the remainder items of its scale and should exceed 0.40 .

Test-retest reliability of each scale was assessed by Pearson's correlations between the scores from the 41 patients who were interviewed twice. As with Cronbach's alpha, test-retest reliability coefficients $>0.70$ were considered adequate for group comparisons [8].

Besides the IQOLA approach for examining the internal validity and reliability, external construct validity was assessed by Spearman's correlations between scores on the AS-20 scales and the clinical measures of disease activity: unilateral visual acuity loss, diplopia and angle of horizontal and vertical strabismus. We expected that diplopia assessment correlated better with F scale, angle of strabismus with $\mathrm{P}$ scale. We expected that unilateral visual acuity loss was not significant correlated with none of the scale, because this questionnaire doesn't focus the attention on amblyops problems. 


\section{Results}

\section{Patient characteristics}

A total of 138 Italian consecutive patients agreed to participate in the study. There were $82(59 \%)$ female and 56 (41\%) male patients with a mean age of 38 (range:17-79) years. One hundred patients (72\%) were patient with strabismus. The duration of strabismus varied between 6 months and 25 years.

For the 100 strabismus patients (median age, 41 years; range, 1779), diagnoses were cranial nerve IV palsy $(n=17)$, decompensated exotropia $(n=5)$, consecutive exotropia $(n=17)$, secondary exotropia $(\mathrm{n}=8)$, Graves' Endocrine Ophthalmopathy $(\mathrm{n}=2)$, infantile esotropia $(n=7)$, partially accommodative esotropia $(n=13)$, decompensated esotropia $(n=5)$, esotropia in myopia $(n=17)$, cranial nerve VI palsy $(n=7)$, cranial nerve III palsy $(n=2)$. Sixty-seven $(67 \%)$ of 100 had diplopia and 33 (33\%) did not. Visual acuity ranged from $20 / 15$ to $20 / 50$ (median, 20/20) for the better eye and 20/15 to $20 / 80$ (median, 20/30) for the worse eye. For the 33 patients with a primary esodeviation, median angle of deviation by prism and alternating cover test (PACT) at distance was 30 prism diopters (pd; range, 10-70). For the 22 patients with a primary exodeviation, median PACT at distance was $40 \mathrm{pd}$ (range, 20-80), for the 17 patients with a primary vertical deviation, median PACT at distance was $16 \mathrm{pd}$ (range, 4-35), and for the 28 patients with a vertical and horizontal deviation, median PACT at distance was $22 \mathrm{pd}$ (range, 4-60) for horizontal deviation and $14 \mathrm{pd}$ (range, 8-30) for vertical deviation.

The 38 visually normal adults (median age, 33 years; range, 19-57) with no history of strabismus or amblyopia were orthotropic and had no more than $10 \mathrm{pd}$ of horizontal and $1 \mathrm{pd}$ of vertical heterophoria by
PACT. For all normal subjects, stereoacuity was 40 seconds of arc using the TNO test, and best-corrected visual acuity was at least 20/25 in each eye (median, 20/20 in each eye).

\section{Acceptability of the final version of AS-20}

Patients did not have problems answering the original questions. No missing values for the individual items of the AS-20 were identified (Table 1). The frequency distribution of individual items indicates that all of the response choices are used. No patients minded answering any of the questions.

\section{Response distribution}

All values were observed for each item (Table 1). Patients showed restrictions on all scales (P and F; Table 2).

\section{Distribution of AS-20 scores}

Mean scales scores ranged from 59.6 (F) to 60.1 (P) (Table 2). A full range of scores was observed in all the scales. Item means were roughly equivalent within a scale, except for item P05 and P06 (87.3 and 11.3, respectively). The percentage of patients scoring at the lowest level was low in the $\mathrm{P}$ and $\mathrm{F}$ scales (16 and 9.1\%, respectively), except for item P06 (72\%). The percentage scoring at the highest level was moderately pronounced ( 36 and $30.9 \%$, respectively). Only item P05 had highest percentage scoring at the highest level (71\%).

\section{Discriminant ability}

The control group of participants had better scale scores across all dimensions of vision-targeted health- related quality of life captured by the AS-20 (Table 3). All comparison between the control group and the patients were statistically significant $(\mathrm{P}<0.001)$. Thus, the translated

Table 1. Item descriptive statistics (patients. $\mathrm{N}=100$ )

\begin{tabular}{|c|c|c|c|c|c|c|c|c|c|}
\hline \multicolumn{5}{|c|}{ Item } & \multicolumn{5}{|c|}{ Response value frequency } \\
\hline Name & Label & $\begin{array}{l}\text { Missing } \\
(\%)\end{array}$ & Mean & SD & $\mathbf{0}$ & 25 & $\mathbf{5 0}$ & 75 & 100 \\
\hline \multicolumn{10}{|c|}{ Scale $=\mathrm{P}($ Psychosocial $)$} \\
\hline P01 & I worry about people will think about my eyes & 0.0 & 53.0 & 35.0 & 17 & 18 & 24 & 18 & 23 \\
\hline P02 & $\begin{array}{l}\text { I feel that people are thinking about my eyes when they don't } \\
\text { say anything }\end{array}$ & 0.0 & 55.0 & 33.5 & 13 & 18 & 29 & 16 & 24 \\
\hline P03 & $\begin{array}{l}\text { I feel uncomfortable when people are looking at me because of } \\
\text { my eyes }\end{array}$ & 0.0 & 50.5 & 35.4 & 20 & 17 & 25 & 17 & 21 \\
\hline P04 & $\begin{array}{l}\text { I wonder what people are thinking when they are looking at me } \\
\text { because of my eyes }\end{array}$ & & 55.0 & 35.9 & 15 & 22 & 18 & 18 & 27 \\
\hline P05 & People don’t give me opportunities because of my eyes & 0.0 & 87.3 & 22.6 & 1 & 3 & 13 & 12 & 71 \\
\hline P06 & I am self-conscious about my eyes & 0.0 & 11.3 & 22.6 & 72 & 19 & 4 & 2 & 3 \\
\hline $\mathrm{P} 07$ & People avoid looking at me because of my eyes & 0.0 & 82.5 & 25.7 & 2 & 5 & 15 & 17 & 61 \\
\hline P08 & I feel inferior to others because of my eyes & 0.0 & 68.2 & 33.1 & 5 & 16 & 25 & 8 & 45 \\
\hline P09 & People react differently to me because of my eyes & 0.0 & 78.8 & 25.7 & 1 & 6 & 22 & 19 & 52 \\
\hline P10 & $\begin{array}{l}\text { I find it hard to initiate contact with people I don't know because } \\
\text { of my eyes }\end{array}$ & 0.0 & 59.5 & 36.4 & 14 & 18 & 17 & 18 & 33 \\
\hline \multicolumn{10}{|c|}{ Scale $=F($ Function $)$} \\
\hline F01 & I cover or close one eye to see things better & 0.0 & 56.8 & 36.6 & 14 & 22 & 19 & 13 & 32 \\
\hline F02 & I avoid reading because of my eyes & 0.0 & 76.3 & 31.5 & 3 & 15 & 13 & 12 & 57 \\
\hline F03 & $\begin{array}{l}\text { I stop doing things because of my eyes make it difficult to } \\
\text { concentrate }\end{array}$ & 0.0 & 71.3 & 27.1 & 0 & 15 & 22 & 26 & 37 \\
\hline F04 & I have problems with depth perception & 0.0 & 64.8 & 31.0 & 7 & 12 & 27 & 23 & 31 \\
\hline F05 & My eyes feel strained & 0.0 & 41.3 & 24.2 & 11 & 33 & 40 & 12 & 4 \\
\hline F06 & I have problems reading because my eye condition & 0.0 & 59.0 & 37.4 & 17 & 13 & 22 & 13 & 35 \\
\hline F07 & I feel stressed because of my eyes & 0.0 & 53.5 & 31.8 & 8 & 28 & 28 & 14 & 22 \\
\hline F08 & I worry about my eyes & 0.0 & 39.3 & 33.8 & 26 & 28 & 24 & 7 & 15 \\
\hline F09 & I can't enjoy my hobbies because of my eyes & 0.0 & 75.5 & 30.6 & 5 & 9 & 16 & 19 & 51 \\
\hline F10 & I need to take frequent breaks when reading because of my eyes & 0.0 & 58.3 & 34.5 & 13 & 19 & 15 & 28 & 25 \\
\hline
\end{tabular}


Table 2. Descriptive statistics for scales (Patients. N=100)

\begin{tabular}{|c|c|c|c|c|c|c|c|}
\hline \multicolumn{3}{|c|}{ Raw scores } & \multicolumn{3}{c|}{ Observed values } & & \\
\hline Scale & Mean & SD & Lowest & Highest & Range & $\begin{array}{c}\text { \% at } \\
\text { floor }\end{array}$ & $\begin{array}{c}\text { \% at } \\
\text { ceiling }\end{array}$ \\
\hline P & 60.1 & 24.1 & 0 & 100 & 100 & 16 & 36 \\
\hline F & 59.6 & 23.7 & 0 & 100 & 100 & 9.1 & 30.9 \\
\hline
\end{tabular}

Raw Score: Sum of item scores for the scale

: percentage of respondents at the lowest possible scale score

: percentage of respondents at the highest possible scale score

Abbreviations: $\mathrm{F}=$ Function; $\mathrm{P}=$ Psychosocial.

Table 3. Comparison between controls $(\mathrm{N}=38)$ and patients $(\mathrm{N}=100)$ of the italian AS-20 version

\begin{tabular}{|c|c|c|c|}
\hline Scale & Controls Mean \pm SD & Patients Mean \pm SD & $\mathbf{P}^{\star}$ \\
\hline Psychosocial & $91.9 \pm 6.5$ & $60.1 \pm 24.1$ & $<0.001$ \\
\hline Function & $92.4 \pm 5.7$ & $59.8 \pm 19.4$ & $<0.001$ \\
\hline
\end{tabular}

"Mean -Whithney test

questionnaire can be said to have good discrimatory power between patients and healthy controls.

\section{Internal construct validity}

Principal component analysis identified two underlying factors, one representing the "phsycosocial" aspects of health and one representing the "function" aspects of health, which together explained $60.7 \%$ of the total variance. Correlations between the scales and their components largely confirmed the measurement model of the AS-20. (Table 4). The responses to items in the original hypothesized scales are appropriately associated with the factors. One questions "I am self-conscious about my eyes" (P06) had a factor loading of $<0.50$ on all factors.

The correlations between the scales (Table 5) was 0.32 , most well below the preset 0.70 limits for distinctiveness of the concept being measured.

\section{Tests of scaling assumptions}

Standard deviations of the items within the scales were generally comparable (Table 6). Corrected correlations between the items and their hypothesized scales ranged from 0.36 to 0.84 and were 0.4 or above for all items except for one item from the P scale (P06: I am selfconscious about my eyes).

Generally, items were significantly highly correlated with their hypothesized scale (i.e., $>2$ SE) than with the other scales. Exceptions to this were items "I am self-conscious about my eyes" (P06) and "I worry about my eyes "(F08); however, item-scale correlation is higher for the hypothesized scale than for competing scales but not significantly. Consequently, the scaling success rate on discriminant validity was $90 \%$ for all scales (Table 7). Cronbach's alpha ranged from $0.92(\mathrm{P})$ to 0.91 (F) and exceeded the 0.70 standard for all scales.

\section{Test - retest reliability}

Test-retest reliability ranged from 0.97 to 0.98 (Table 7) and was adequate for all scales.

\section{External construct validity}

Correlations between the subscales of AS-20 and the clinical parameters are shown in Table 8. Correlations ranged from 0.11 ( $\mathrm{P}$ vs. diplopia assesment) to -0.45 (F vs. diplopia assessment). Among the correlations with the clinical parameters studied, the $\mathrm{P}$ scale correlated best with the angle of horizontal strabimsus $(\mathrm{P}<.05)$; the F scale correlated best with the level of diplopia $(\mathrm{P}<.001)$. The level of unilateral acuity loss and angle of vertical strabismus were not correlated significantly with none of the scale.

\section{Discussion}

An important consideration when using an HRQOL questionnaire is the cultural appropriateness of the measure. In this study, the standard US English AS-20 was cross-culturally translated and adapted for use in the Italian culture in accordance with standard methodology (Table 9).

The findings showed that Italian AS-20 appears to be an acceptable, reliable, and valid instrument for measuring HRQOL in Italian patients with strabismus.

Table 4. Results of factor analysis (PCA and Varimax rotation) within the two AS-20 dimensions

\begin{tabular}{|c|c|c|c|}
\hline \multicolumn{2}{|l|}{ Item } & \multicolumn{2}{|c|}{$\begin{array}{l}\text { Two-factor } \\
\text { solution }\end{array}$} \\
\hline Name & Label & 1 & 2 \\
\hline \multicolumn{4}{|c|}{ Scale $=\mathbf{P}($ Psychosocial $)$} \\
\hline P01 & I worry about people will think about my eyes & 0.88 & -0.01 \\
\hline $\mathrm{P} 02$ & $\begin{array}{l}\text { I feel that people are thinking about my eyes when they } \\
\text { don't say anything }\end{array}$ & 0.88 & -0.03 \\
\hline P03 & $\begin{array}{l}\text { I feel uncomfortable when people are looking at me because } \\
\text { of my eyes }\end{array}$ & 0.89 & -0.07 \\
\hline P04 & $\begin{array}{l}\text { I wonder what people are thinking when they are looking at } \\
\text { me because of my eyes }\end{array}$ & 0.89 & 0.05 \\
\hline P05 & People don't give me opportunities because of my eyes & 0.68 & -0.02 \\
\hline P06 & I am self-conscious about my eyes & 0.40 & 0.14 \\
\hline P07 & People avoid looking at me because of my eyes & 0.71 & -0.24 \\
\hline P08 & I feel inferior to others because of my eyes & 0.71 & 0.33 \\
\hline P09 & People react differently to me because of my eyes & 0.74 & 0.20 \\
\hline P10 & $\begin{array}{l}\text { I find it hard to initiate contact with people I don't know } \\
\text { because of my eyes }\end{array}$ & 0.82 & 0.23 \\
\hline \multicolumn{4}{|c|}{ Scale $=\mathbf{F}($ Function $)$} \\
\hline F01 & I cover or close one eye to see things better & 0.13 & 0.73 \\
\hline F02 & I avoid reading because of my eyes & -0.02 & 0.78 \\
\hline F03 & $\begin{array}{l}\text { I stop doing things because of my eyes make it difficult to } \\
\text { concentrate }\end{array}$ & 0.06 & 0.83 \\
\hline F04 & I have problems with depth perception & 0.07 & 0.50 \\
\hline F05 & My eyes feel strained & 0.07 & 0.67 \\
\hline F06 & I have problems reading because my eye condition & 0.02 & 0.88 \\
\hline F07 & I feel stressed because of my eyes & 0.34 & 0.74 \\
\hline F08 & I worry about my eyes & 0.50 & 0.51 \\
\hline F09 & I can’t enjoy my hobbies because of my eyes & 0.35 & 0.70 \\
\hline F10 & $\begin{array}{l}\text { I need to take frequent breaks when reading because of my } \\
\text { eyes }\end{array}$ & 0.00 & 0.88 \\
\hline \multicolumn{4}{|c|}{ Unrotated solution } \\
\hline \multicolumn{2}{|c|}{ Eigenvalue } & 7.83 & 4.31 \\
\hline \multicolumn{2}{|c|}{$\%$ Variance explained } & 39.17 & 21.56 \\
\hline \multicolumn{2}{|c|}{$\%$ Cumulative variance explained } & 39.17 & 60.73 \\
\hline \multicolumn{4}{|c|}{ Rotated solution } \\
\hline \multicolumn{2}{|c|}{ Eigenvalue } & 6.49 & 5.66 \\
\hline \multicolumn{2}{|c|}{$\%$ Variance explained } & 32.44 & 28.28 \\
\hline
\end{tabular}

Factor loadings $>0.50$ are in bold. The table shows that the six two non-rotated factors explained $39.2 \%$, and $21.6 \%$, together representing $60.7 \%$ of the item variance. The hypothesized HRQoL domains matched with the underling factors found by the factor analysis.

Table 5. Reliability coefficients and inter-scale correlations (patients; $N=100$ ).

\begin{tabular}{|c|c|c|}
\hline Scale & Psychosocial & Function \\
\hline Psychosocial & $(0.92)$ & \\
\hline Function & 0.32 & $(0.91)$ \\
\hline
\end{tabular}

Scale internal consistency reliability (Cronbach's alpha coefficient) is presented in the diagonal. 
Table 6. Item descriptive statistics and Pearson item-scale correlations corrected for overlap (patients. N=100)

\begin{tabular}{|c|c|c|c|c|c|}
\hline \multicolumn{4}{|l|}{ Item } & \multicolumn{2}{|c|}{ Pearson item-scale correlations* } \\
\hline Name & Label & Mean & SD & $\mathbf{P}$ & $\mathbf{F}$ \\
\hline \multicolumn{6}{|c|}{ Scale $=\mathrm{P}($ Psychosocial $)$} \\
\hline P01 & I worry about people will think about my eyes & 53.0 & 35.0 & $0.82 *$ & 0.18 \\
\hline $\mathrm{P} 02$ & I feel that people are thinking about my eyes when they don't say anything & 55.0 & 33.5 & $0.82 *$ & 0.16 \\
\hline $\mathrm{P} 03$ & I feel uncomfortable when people are looking at me because of my eyes & 50.5 & 35.4 & $0.84^{*}$ & 0.12 \\
\hline P04 & I wonder what people are thinking when they are looking at me because of my eyes & 55.0 & 35.9 & $0.85^{*}$ & 0.23 \\
\hline $\mathrm{P} 05$ & People don't give me opportunities because of my eyes & 87.3 & 22.6 & $0.61^{*}$ & 0.09 \\
\hline P06 & I am self-conscious about my eyes & 11.3 & 22.6 & 0.36 & 0.21 \\
\hline P07 & People avoid looking at me because of my eyes & 82.5 & 25.7 & $0.66^{*}$ & 0.37 \\
\hline P08 & I feel inferior to others because of my eyes & 68.2 & 33.1 & $0.69^{*}$ & 0.45 \\
\hline P09 & People react differently to me because of my eyes & 78.8 & 25.7 & $0.70^{*}$ & 0.31 \\
\hline P10 & I find it hard to initiate contact with people I don't know because of my eyes & 59.5 & 36.4 & $0.81^{*}$ & 0.37 \\
\hline \multicolumn{6}{|c|}{ Scale $=\mathrm{F}($ Function $)$} \\
\hline F01 & I cover or close one eye to see things better & 56.8 & 36.6 & 0.20 & $0.68 *$ \\
\hline F02 & I avoid reading because of my eyes & 76.3 & 31.5 & 0.09 & $0.69^{*}$ \\
\hline F03 & I stop doing things because of my eyes make it difficult to concentrate & 71.3 & 27.1 & 0.17 & $0.76^{*}$ \\
\hline F04 & I have problems with depth perception & 64.8 & 31.0 & 0.13 & $0.42 *$ \\
\hline F05 & My eyes feel strained & 41.3 & 24.2 & 0.15 & $0.59^{*}$ \\
\hline F06 & I have problems reading because my eye condition & 59.0 & 37.4 & 0.14 & $0.82 *$ \\
\hline F07 & I feel stressed because of my eyes & 53.5 & 31.8 & 0.41 & $0.72 *$ \\
\hline F08 & I worry about my eyes & 39.3 & 33.8 & 0.52 & $0.53 *$ \\
\hline F09 & I can’t enjoy my hobbies because of my eyes & 75.5 & 30.6 & 0.41 & $0.71 *$ \\
\hline F10 & I need to take frequent breaks when reading because of my eyes & 58.3 & 34.5 & 0.12 & $0.80^{*}$ \\
\hline
\end{tabular}

* Item-scale correlation corrected for overlap (relevant item removed from its scale for correlation)

Table 7. Test of scaling assumptions (Cronbach's alpha, item internal consistency, item discriminant validity, and scaling success) $($ patients; $\mathrm{N}=100)$ and test -retest reliability ( $\mathrm{n}=41)$.

\begin{tabular}{|c|c|c|c|c|c|c|c|}
\hline \multicolumn{5}{|c|}{ Correlations between items and scales } & \multicolumn{3}{|c|}{ Scaling success } \\
\hline Scale & \# Items & Cronbach's alpha & $\begin{array}{l}\text { Item internal } \\
\text { consistency }^{\mathrm{a}}\end{array}$ & $\begin{array}{c}\text { Item discriminant } \\
\text { validity }^{\mathrm{b}}\end{array}$ & Success/total ${ }^{\mathrm{c}}$ & Scaling success $(\%)$ & $\begin{array}{c}\text { Test - retest } \\
\text { (Pearson's r) }\end{array}$ \\
\hline Psychosocial & 10 & 0.92 & $0.36-0.85$ & $0.18-0.45$ & $9 / 10$ & 90 & 0.97 \\
\hline Function & 10 & 0.91 & $0.42-0.82$ & $0.09-0.52$ & $9 / 10$ & 90 & 0.98 \\
\hline
\end{tabular}

P-values $<0.05$ for all correlation coefficients

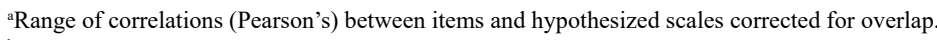

'Range of correlations (Pearson's) between items and other scales.

${ }^{c}$ Number of significantly higher ( $>2$ standard errors) correlations between items and hypothesized scales/number of correlations.

Table 8. Spearman correlation between scales and clinical parameters (patients)

\begin{tabular}{|c|c|c|c|c|}
\hline Scale & $\begin{array}{c}\text { Level of } \\
\text { unilateral } \\
\text { acuity loss } \\
(\mathbf{n = 1 0 0 )}\end{array}$ & $\begin{array}{c}\text { Diplopia } \\
\text { assessment } \\
(\mathbf{n}=\mathbf{9 8})\end{array}$ & $\begin{array}{c}\text { Angle horizontal } \\
\text { strabismus } \\
(\mathbf{n}=\mathbf{9 8})\end{array}$ & $\begin{array}{c}\text { Angle vertical } \\
\text { strabismus } \\
(\mathbf{n}=\mathbf{3 0})\end{array}$ \\
\hline Psychosocial & -0.04 & 0.11 & $\mathbf{- 0 . 3 1 ^ { \mathbf { a } }}$ & -0.11 \\
\hline Function & 0.08 & $\mathbf{- 0 . 4 5}^{\mathbf{c}}$ & 0.01 & -0.19 \\
\hline
\end{tabular}

*Listed is the Spearman rank correlation coefficient $\mathrm{r}_{\mathrm{s} .}$ Significant correlations are listed in bold ( ${ }^{\mathrm{a}} \mathrm{P}<.05$, $\left.{ }^{\mathrm{b}} \mathrm{P}<.01,{ }^{\mathrm{c}} \mathrm{P}<.001\right)$. All significant associations have negative correlation coefficients because more favorable AS-20 scores are higher, while more favorable disability scores and clinical parameters are lower.

As expected, the mean score in the patients group was much lower than controls.

No significant floor and ceiling problems were found except for items P05 and P06.

Principal component analysis supported the existence of the two hypothesized "psychosocial" and "function" dimensions. Also, the observed correlational pattern between AS-20 scales and the rotated components showed higher correlations of psychosocial scale with the first factor, whereas the function scale correlated weakly with this factor. The reverse was found with the second factor. The correlations of the scales with their principal components were similar to the hypothesized measurement model of the AS-20 and those found in US patients.
One item, P06 ("I am self-conscious about my eyes") had a factor loading of $<0.50$ on all factors." However, the factor analysis identified an although weak correlation (0.40) with the hypothesized scale "Psychosocial".

All items passed the test of item internal consistency with the exception of one P items P06 ("I am self-conscious about my eyes").

With the exception of items P06 ("I am self-conscious about my eyes") and "I worry about my eyes "(F08), all items passed also the test for discriminant validity.

As expected the item P06 could be misunderstood and for these reasons item P06 may be eliminated from the final Italian version of AS-20.

This study also provided support for the reliability of the Italian AS-20. The reliability of all scales was well above the 0.70 standard for group comparison.

The test- retest reliability of the Italian AS-20 (ranging from 0.97 to $0.98)$ was adequate for all scales.

Significant correlations were found between the AS-20 scales and the clinical parameters, in particular P scale correlated best with the angle of horizontal strabismus, the F scale correlated best with the level of diplopia, confirming the external construct validity of the italian AS- 
Table 9. Italian version of Adult strabismus 20 questionnaire

\begin{tabular}{|c|l|}
\hline \multicolumn{2}{|c|}{ Item } \\
\hline Name & Label \\
\hline Scale $=$ P $($ Psychosocial) \\
\hline P01 & Sono preoccupato/a di ciò che la gente possa pensare dei miei occhi \\
\hline P02 & Mi accorgo che la gente pensa ai miei occhi anche quando non dice niente \\
\hline P03 & Mi sento a disagio quando la gente mi guarda a causa dei miei occhi \\
\hline P04 & Mi domando cosa pensa la gente quando mi guarda, a causa dei miei occhi \\
\hline P05 & La gente non mi offre opportunità a causa dei miei occhi \\
\hline P06 & La gente evita di guardarmi a causa dei miei occhi \\
\hline P07 & Mi sento inferiore agli altri a causa dei miei occhi \\
\hline P08 & $\begin{array}{l}\text { La gente reagisce in maniera diversa nei miei confronti a causa dei miei } \\
\text { occhi }\end{array}$ \\
\hline P09 & $\begin{array}{l}\text { Mi trovo in difficoltà a rapportarmi con persone che non conosco a causa } \\
\text { dei miei occhi }\end{array}$ \\
\hline Scale= F (Function) \\
\hline F01 & Chiudo o mi copro un occhio per vedere le cose meglio \\
\hline F02 & Evito di leggere a causa dei miei occhi \\
\hline F03 & $\begin{array}{l}\text { Interrompo quello che sto facendo perché non riesco a concentrarmi a causa } \\
\text { dei miei occhi }\end{array}$ \\
\hline F04 & Ho problemi nella percezione della profondità \\
\hline F05 & Sento gli occhi stanchi \\
\hline F06 & Ho problemi a leggere a causa della condizione dei miei occhi \\
\hline F07 & Mi sento stressato a causa dei miei occhi \\
\hline F08 & Sono preoccupato per i miei occhi \\
\hline F09 & Non posso praticare i miei hobbies a causa dei miei occhi \\
\hline F10 & Ho necessità di fare frequenti pause quando leggo a causa dei miei occhi \\
\hline & \\
\hline
\end{tabular}

20. It appeared that the F scale was more influenced by the angle of horizontal strabismus than vertical one.

In summary, the Italian AS-20 appears to be an acceptable, reliable, and valid instrument for measuring HRQOL in patients with strabismus.

\section{Research involving human participants and/ or animals}

Statement of human rights
Ethical approval: All procedures performed in studies involving human participants were in accordance with the ethical standards of the institutional and/or national research committee and with the 1964 Helsinki declaration and its later amendments or comparable ethical standards.

Statement on the welfare of animals

This chapter does not contain any studies with animals performed by any of the authors

\section{Informed consent}

Informed consent: Informed consent was obtained from all individual participants included in the study.

\section{References}

1. Bowling A. Measuring disease: a review of disease specific quality of life measurement scales. 2nd ed. Buckingham, UK: Open University Press; 2001

2. Fayers PM, Machin D. Quality of life: the assessment, analysis and interpretation of patient-reported outcomes. 2nd ed. Chichester, UK: Wiley; 2007.

3. Patrick DL, Deyo RA (1989) Generic and disease-specific measures in assessing health status and quality of life. Med Care 27: S217-232. [Crossref]

4. Hatt SR, Leske DA, Bradley EA, Cole SR, Holmes JM (2009) Development of a quality-of-life questionnaire for adults with strabismus. Ophthalmology 116: 139-144. [Crossref]

5. Berzon R, Hays RD, Shumaker SA (1993) International use, application and performance of health-related quality of life instruments. Qual Life Res 2: 367-368. [Crossref]

6. Beaton DE, Bombardier C, Guillemin F, Ferraz MB (2000) Guidelines for the process of cross-cultural adaptation of self-report measures. Spine (Phila Pa 1976) 25: 3186 3191. [Crossref]

7. Massof RW (1998) A systems model for low vision rehabilitation. II. Measurement of vision disabilities. Optom Vis Sci 75: 349-373. [Crossref]

8. Ware JE Jr, Gandek B (1998) Methods for testing data quality, scaling assumptions, and reliability: the IQOLA Project approach. International Quality of Life Assessment. $J$ Clin Epidemiol 51: 945-952. [Crossref]

Copyright: (C2017 Marcon GB. This is an open-access article distributed under the terms of the Creative Commons Attribution License, which permits unrestricted use, distribution, and reproduction in any medium, provided the original author and source are credited. 